\title{
Serum concentrations of HGF and IL-8 in patients with active Graves' orbitopathy before and after methylprednisolone therapy
}

\author{
M. Nowak ${ }^{1}$ L. Siemińska ${ }^{1}$ J. Karpe ${ }^{3} \cdot$ B. Marek $^{1} \cdot$ B. Kos-Kudła ${ }^{2}$ D. Kajdaniuk ${ }^{1}$
}

Received: 16 January 2015 / Accepted: 22 May 2015 / Published online: 11 June 2015

(C) The Author(s) 2015. This article is published with open access at Springerlink.com

\begin{abstract}
Introduction Graves' disease is the most common cause of hyperthyroidism, and orbitopathy is the most frequent extrathyroidal manifestation of Graves' disease. The aims of this study were as follows: (1) to evaluate the serum concentration of HGF and IL-8 in the blood of newly diagnosed Graves' disease patients with the first episode of active GO and healthy controls; (2) to estimate the influence of the thyroid function (euthyreosis vs. hyperthyreosis) on HGF and IL-8 blood levels in patients with active GO; (3) to evaluate the influence of intravenous (i.v.) methylprednisolone (MP) pulse therapy and additional oral MP treatment on HGF and IL-8 blood levels in patients with active GO.

Patients and methods Thirty-nine Graves' disease patients with the first episode of clinically active GO (Group A) were enrolled in the study. To estimate the influence of the thyroid function on serum concentrations of the studied proangiogenic factors, Group A was divided into Group A I $(n=18)$ in euthyroid and Group A II $(n=21)$ in hyperthyroid stage of Graves' disease in moderate-to-severe stage of GO. The control group consisted of 20 healthy volunteers
\end{abstract}

M. Nowak

nowak-mar@wp.pl

1 Pathophysiology Division, Department of Pathophysiology and Endocrinology, School of Medicine with the Division of Dentistry, Medical University of Silesia, pl. Traugutta 2, 41-800 Zabrze, Poland

2 Endocrinology Division, Department of Pathophysiology and Endocrinology, School of Medicine with the Division of Dentistry, Medical University of Silesia, Zabrze, Poland

3 Department of Anaesthesiology and Intensive Therapy, School of Medicine with the Division of Dentistry, Medical University of Silesia, Zabrze, Poland age- and sex-matched to the GO group. Concentrations of the studied proangiogenic factors in serum samples were measured by an enzyme-linked immunosorbent assay before (Group A) and after (Group A1) intensive pulse i.v.MP treatment and 1 month after the end of additional oral MP treatment (Group A2).

Results We found a significant increase in serum concentrations of studied factors in the GO group before immunosuppressive therapy when compared with the control group and decrease after i.v.MP treatment. One month after the end of additional oral MP treatment (Group A2), serum concentrations of HGF and IL-8 still decreased and no significant difference was observed in HGF and IL-8 concentrations when compared with the control group. We did not find the difference in serum concentration of the studied proangiogenic factors between patients in euthyroid and hyperthyroid stage of Graves' disease before MP therapy.

Conclusions Serum HGF and IL-8 concentrations are elevated in Graves' disease patients with active Graves' orbitopathy as compared to the healthy control group. Successful management of active Graves' orbitopathy with glucocorticoids is associated with a decrease in HGF and IL-8 serum concentrations.

Keywords Graves' orbitopathy $\cdot$ Hepatocyte growth factor · Interleukin- $8 \cdot$ Methylprednisolone treatment

\section{Introduction}

Graves' disease is the most common cause of hyperthyroidism, and orbitopathy is the most frequent extrathyroidal manifestation of Graves' disease [1]. Graves' orbitopathy (GO) is the complex of periocular and/or ocular manifestations that are often found in patients with Graves' 
disease but also, less frequently, in patients with Hashimoto thyroiditis or patients without thyroid abnormalities [2]. Graves' orbitopathy occurs before, during, or after the onset of hyperthyroidism and, less frequently, in euthyroid or hypothyroid patients. The course of GO can be divided into active (infiltrative) and inactive (fibrotic) phases.

The estimated incidence of GO in the general population is 16 females and 3 males per 100,000 persons annually, with severe forms accounting for no more than 3-5\% of the cases [3]. The female-to-male ratio is $9.3: 1$ in patients with mild GO, 3.2:1 in patients with moderate, and 1.4:1 with severe GO [4].

Graves' orbitopathy is an autoimmune disease in which CD4+ and CD8 + T cells, B cells, plasma cells, and macrophages infiltrate the orbital and periorbital soft tissues, which results in tissue remodelling and oedema. Enlargement of the orbital tissue volume occurs through the accumulation of the extracellular matrix, scar-forming myofibroblasts, and/or fat proliferation [5, 6]. Orbital $\mathrm{T}$ cells, fibroblasts, adipocytes and perhaps other residential cells may release numerous cytokines, growth factors, and inflammatory mediators, many of which act as potent stimulators of glycosaminoglycan accumulation and oedema formation. Numerous cytokines, such as IL-1 $\alpha$, IL-4, IL-6, IL-8, IL-10, IL-16, TNF- $\alpha$, CCL2, and CXCL10 were identified in the orbital tissue and serum from patients with GO and are, therefore, proposed to play a significant role in GO pathogenesis [7-10].

The thyroid-stimulating hormone (TSH) receptor (TSHR) is the autoantigen responsible for the hyperthyroidism in Graves' disease and is considered an important contributor to GO. The major autoantigens in Hashimoto's disease are thyroid peroxidase (TPO) and thyroglobulin (Tg). However, these antibodies (anti-TPO and anti-Tg) also occur in about $70 \%$ of Graves' disease patients [11]. Thyroid-stimulating hormone receptor antibodies (TRAb) are present in all patients with Graves' disease, and the severity and the activity of GO directly correlate positively with the blood TRAb levels [12-14].

It is suggested that insulin-like growth factor-1 receptor (IGF-1R) stimulatory autoantibodies enhance the production of hyaluronan and $\mathrm{T}$ cell chemoattractants (IL-16 and CCL5) by orbital fibroblasts and/or recruited fibrocytes [15]. Other autoantigens were also proposed as putative shared antigens, including several eye muscle antigens or acetylcholine receptor [16]. It remains to be established whether autoimmunity to TSHR is the primary event. However, the role of other autoantigens in the development of GO has not been fully understood as yet.

Angiogenesis, formation of new vascular structures from preexisting vessels, occurs in several organs during multiple pathophysiological conditions. Although it is an integral part of tumour progression, angiogenesis is also observed in different inflammatory, fibrotic, and ischaemic diseases [17-19].

A limitation in oxygen supply is an important stimulus for proangiogenic factors expression. Hypoxia promotes the expansion of monoclonal cells, which have lost their ability to induce apoptosis in response to hypoxia [20]. Lower cellular $\mathrm{pH}$ and a higher concentration of lactate could induce the release of proangiogenic factors from macrophages and tumour cells [21]. In GO, the restricted orbital compartment is associated with compression of orbital tissue and slow venous return [22]. This may result in a limitation in the oxygen supply, lower $\mathrm{pH}$, and a higher concentration of lactate which could stimulate the proangiogenic factors expression, independently of other mechanisms such as inflammation. Among the mechanical factors that trigger angiogenesis, an important role is played by increased blood flow in the vascular capillary (e.g. hyperthyroidism) [23].

Activators of angiogenesis include vascular endothelial growth factor (VEGF), hepatocyte growth factor (HGF), transforming growth factor beta 1 (TGF $\beta 1$ ), and its receptors, acidic and basic fibroblast growth factor (aFGF, bFGF), insulin-like growth factor I (IGF-I), platelet-derived growth factor (PDGF), nitric oxide (NO), plasminogen activators (uPA - urokinase plasminogen activator), matrixmetalloproteinases (MMPs), heparinases, chymases, tryptase, cathepsin, angiopoietin-1 (Ang-1) and angiopoietin-2 (Ang-2), plasminogen activator inhibitor 1 (PAI-1), angiotensin II, monocyte chemotactic protein 1 (MCP-1), hypoxia-inducible factor 1 alpha (HIF-1 $\alpha$ ), IL-8 and IL-1, epidermal growth factor (EGF), prostaglandin (PGE 1, PGE 2, PGF), erythropoietin, histamine, bradykinin, fibrin, heparin, and tumour necrosis factor alpha (TNF $\alpha)$ [23, 24].

According to the current guidelines of the European Group on Graves' Orbitopathy, euthyroidism should be restored and maintained stably in all patients with GO $[25,26]$. In the cases of moderate-to-severe GO, intravenous glucocorticoid therapy is the first line treatment [25]. Therefore, patient selection and treatment risks must be adequately addressed, since available therapies for GO are associated with potentially serious adverse effects [27]. This is an area where new treatment approaches are greatly needed. In previous papers, authors found an important role of different proangiogenic factors such as VEGF, PDGF, or TGF $\beta 1$ in the pathogenesis of GO and its correlation with clinical activity of the disease [5, 28-30].

It is known that HGF is a powerful inducer of angiogenesis with the activity compared to VEGF [31, 32]. Orbital inflammation in active GO is dominated by a T-helper 1 (Th1) cytokine environment with abundant production of cytokines such as IL- $1 \beta$, IL- 2 , IFN- $\gamma$, and TNF- $\alpha$ and it was demonstrated that IL- $1 \beta$ stimulates orbital fibroblasts to produce Interleukin-8 (IL-8) which is a chemoattractant 
for B-lymphocytes, neutrophils, monocytes, and T-lymphocytes $[33,34]$.

The aims of this study were as follows: (1) to evaluate the serum concentration of HGF and IL-8 in the blood of newly diagnosed Graves' disease patients with the first episode of active GO and healthy controls; (2) to estimate the influence of the thyroid function (euthyreosis vs. hyperthyreosis) on HGF and IL-8 blood levels in patients with active $\mathrm{GO}$; (3) to evaluate the influence of intravenous methylprednisolone (MP) pulse therapy and additional oral MP therapy on HGF and IL-8 blood levels in patients with active GO.

The work was supported by the research programme (KNW-1-129/K/3/0) of the Committee of Scientific Research in Poland.

\section{Patients and methods}

Thirty-nine Graves' disease patients with the first episode of clinically active GO (Group A) were enrolled in the study. To estimate the influence of the thyroid function on serum concentrations of the studied proangiogenic factors, Group A was divided into Group A I $(n=18)$ in euthyroid and Group A II $(n=21)$ in hyperthyroid stage of Graves' disease. The control group consisted of 20 healthy volunteers age- and sex-matched to the GO group [mean age $52.8 \pm 7.6$, min 34 max 64 years; male/female ratio: 5/15 $(25 / 75 \%)]$ without thyroid disease, autoimmune diseases, liver diseases, or history of immunosuppressive therapy.

All patients enrolled in the GO group were treated with anti-thyroid drugs (thiamazole) and mean duration after onset of GO was 4.6 months (min 1 month, max 7 months). Patients in the studied group were in moderate-to-severe stage of GO, according to the European Group on Graves' Orbitopathy classification [25]. Epidemiological and clinical characteristics of the studied group of patients with active GO are presented in Table 1 .

The inclusion criteria for the study were the following: confirmation of Graves' disease by clinical and laboratory findings [free thyroxine-fT4, TSH, TSH-receptor antibodies (TRAb) and, thyroid USG scans-enlargement of thyroid gland with typical diffuse increased vascularity] and ophthalmological examination confirming the active stage of GO (clinical activity score-CAS $\geq 3$ points, magnetic resonance scans of the orbit). The exclusion criteria were any other causes of exophthalmos, other immune system disorders, other metabolic and infectious diseases, previous history of immunosuppressive therapy, and patients with malignant tumours.

All patients enrolled for the study were diagnosed and treated in Endocrinology Division, Department of Pathophysiology and Endocrinology, Medical University of
Table 1 Clinical characteristics of the patients with active Graves' orbitopathy (GO) (Group A) and patients with GO in euthyroid ( $n=18$, Group A I) and hyperthyroid $(n=21$, Group A II) stage of thyroid function before methylprednisolone treatment

\begin{tabular}{llll}
\hline & Group A $(n=39)$ & $\begin{array}{l}\text { Group A I } \\
(n=18)\end{array}$ & $\begin{array}{l}\text { Group A II } \\
(n=21)\end{array}$ \\
\hline Age (years) & $50 \pm 9.4$ & $51 \pm 10.7$ & $49 \pm 8.4$ \\
Male/female & $8 / 31$ & $4 / 14$ & $4 / 17$ \\
& $(20.5 / 79.5 \%)$ & $(28.6 / 71.4 \%)$ & $(23.5 / 76.5 \%)$ \\
TRAb (IU/l) & $16.776 \pm 43.653$ & $7.695 \pm 14.726$ & $24.559 \pm 57.432$ \\
TSH $(\mu \mathrm{IU} / \mathrm{ml})$ & $1.467 \pm 3.375$ & $3.121 \pm 4.481$ & $0.050 \pm 0.077$ \\
FT4 $(\mathrm{ng} / \mathrm{dl})$ & $2.756 \pm 7.088$ & $1.168 \pm 0.479$ & $4.116 \pm 9.542$ \\
CAS & $5.692 \pm 1.127$ & $5.667 \pm 1.328$ & $5.714 \pm 0.956$ \\
NO SPECS & $4.079 \pm 0.969$ & $4.118 \pm 0.781$ & $4.048 \pm 1.117$ \\
\hline
\end{tabular}

Values are mean \pm standard deviation

$T R A b$ TSH-receptor antibodies, CAS clinical activity score of GO, NO SPECS severity classification score of GO

Silesia and GO classification was made by consultant ophthalmologist (M.N.) with high experience in diagnosis and classifications of GO. In all patients the starting dose $0.5 \mathrm{~g}$ daily every other day, intravenous (i.v.) methylprednisolone (MP) infusion was maintained for the six infusions and then, in most cases, halved $(0.25 \mathrm{~g})$ for the remaining three or six infusions to the total maximum cumulative dose of $4.5 \mathrm{~g}$ (within 3 or 4 weeks). All patients obtained the middle cumulative dose of i.v.MP according to the recommendations of the EUGOGO [35]. The cumulative dose of i.v.MP depended on the clinical response to the treatment (ophthalmological assessment performed after six infusions). After i.v.MP therapy, treatment was continued with orally administrated MP in the initial dose of $24-32 \mathrm{mg}$ daily $(0.4 \mathrm{mg} / \mathrm{kg}$ of body weight) with dose reduction during the next 3 months.

Blood was collected after an overnight fast, and serum was obtained by centrifugation and it was stored at $-70{ }^{\circ} \mathrm{C}$. Concentrations of the studied proangiogenic factors in serum samples were measured by an enzyme-linked immunosorbent assay (ELISA) for human HGF (Ray Biotech, Inc., USA) and for IL-8 (Quantikine R\&D System, USA), according to the manufacturer's standard protocol before (Group A) and after (Group A1) intensive pulse i.v.MP treatment and 1 month after the end of additional oral MP treatment (Group A2). Intra- and interassay variations for HGF were 2.9 and $2.6 \%$, and for IL-8 5.6-6.5 and 6.1$7.4 \%$, respectively.

The statistical analysis was performed using the StatSoft Inc. (2011) Statistica v.10 data analysis software system. The distribution of the tested samples was determined by the Kolmogorov-Smirnov test. Kruskal-Wallis one-way analysis of variance with post hoc Dunn test was applied to compare the results in the studied groups of patients. For 
all statistical tests, a $p$ value $<0.05$ was considered to indicate statistical significance.

All subjects gave their informed consent before participating in the study, and the study followed the tenets of the Declaration of Helsinki. The project was conducted with the approval of The Bioethics Board of the Medical University of Silesia (NN-6501-34/06, KNW/0022/KB/35/13).

\section{Results}

The results of the study are presented in Tables 2 and 3 and in Figs. 1 and 2.

We found a significant increase in serum concentrations of the studied proangiogenic factors in the GO group before i.v.MP therapy when compared with the control group [HGF: $1035.0 \pm 465.0$ vs. $567.0 \pm 249.0 \mathrm{pg} /$ $\mathrm{ml}, p=0.001$; IL-8: $28.89 \pm 13.03$ vs. $17.57 \pm 3.4 \mathrm{pg} /$ $\mathrm{ml}, p=0.0002]$. After i.v.MP therapy, we found a significant decrease in IL-8 serum concentrations [19.29 \pm 4.08 vs. $28.89 \pm 13.03 \mathrm{pg} / \mathrm{ml}, p=0.0002]$ and a decrease in HGF though not significant $[771.0 \pm 295.0$ vs. $1035.0 \pm 465.0 \mathrm{pg} / \mathrm{ml}, p=0.670]$ as compared to the concentration before treatment.

One month after the end of additional oral MP treatment (Group A2), serum concentration of HGF decreased insignificantly compared to the concentration in Group
A1 [A2: $678.0 \pm 345.0$ vs. A1: $771.0 \pm 295.0 \mathrm{pg} / \mathrm{ml}$; $p=1.000]$. Serum concentration of HGF was significantly lower after the end of additional oral MP treatment (Group A2) when compared with the concentration in the GO group before i.v.MP therapy (Group A) $[678.0 \pm 345.0$ vs. $1035.0 \pm 465.0 \mathrm{pg} / \mathrm{ml}, p=0.021]$. After the end of additional oral MP treatment (Group A2), no significant difference was observed in HGF concentration when compared with the control group [678.0 \pm 345.0 vs. $567.0 \pm 249.0 \mathrm{pg} /$ $\mathrm{ml}, p=1.000]$. Serum concentration of IL- 8 also decreased after the end of additional oral MP treatment (Group A2) as compared with the concentration in Group A1 [16.9 \pm 4.82 vs. $19.29 \pm 4.08 \mathrm{pg} / \mathrm{ml}, p=0.731$ ], and we found no difference in the value between Group A2 and the control $[17.57 \pm 3.4 \mathrm{pg} / \mathrm{ml}, p=0.994]$.

In the GO group before i.v.MP therapy, the mean CAS score was $5.718 \pm 1.123$ and we found a significant reduction in GO activity after i.v.MP $(3.0 \pm 1.138, p=0.001)$ and a further significant reduction after the end of additional oral MP treatment (Group A2) $(2.178 \pm 1.403$, A1 vs. A2 $p=0.011$ ). Mean severity index of GO measured by the NO SPECS score in Group A was $4.077 \pm 0.957$ and decreased significantly after i.v.MP therapy (A1: $3.4 \pm 0.976, p=0.003$ ). In Group A2, we also observed a reduction in the severity of GO $(2.013 \pm 1.276)$. We did not, however, find a significant difference as compared with the NO SPECS score in Group A1 (A2 vs. A1 $p=0.099$ ).

Table 2 Serum concentration of hepatocyte growth factor (HGF, pg/ml) in the studied groups of patients with active Graves' orbitopathy and the healthy control group

\begin{tabular}{lrlllllr}
\hline Group & Mean & SD & Median & Minimum & Maximum & Lower quartile & Upper quartile \\
\hline A & 1035.0 & 465.0 & 933.0 & 312.0 & 3018.0 & 663.0 & 1284.0 \\
A1 & 771.0 & 295.0 & 741.0 & 162.0 & 1452.0 & 582.0 & 1095.0 \\
A2 & 678.0 & 345.0 & 582.0 & 216.0 & 1818.0 & 459.0 & 798.0 \\
C & 567.0 & 249.0 & 432.0 & 207.0 & 1203.0 & 342.0 & 813.0 \\
\hline
\end{tabular}

A patients with clinically active Graves' orbitopathy (GO) before intensive pulse methylprednisolone treatment, $A 1$ patients with clinically active GO after intensive pulse methylprednisolone treatment, $A 2$ patients with clinically active GO 1 month after the end of additional oral methylprednisolone treatment, $C$ control group

Table 3 Serum concentration of Interleukin 8 (IL-8, pg/ml) in the studied groups of patients with active Graves' orbitopathy and the healthy control group

\begin{tabular}{llllllll}
\hline Group & Mean & SD & Median & Minimum & Maximum & Lower quartile & Upper quartile \\
\hline A & 28.89 & 13.03 & 24.2 & 17.4 & 78.1 & 19.7 & 30.1 \\
A1 & 19.29 & 4.08 & 17.9 & 14.6 & 29.1 & 16.9 & 21.2 \\
A2 & 16.9 & 4.82 & 16.1 & 11.6 & 29.8 & 13.1 & 19.2 \\
C & 17.57 & 3.4 & 16.9 & 12.1 & 23.6 & 15.3 & 20.6 \\
\hline
\end{tabular}

A patients with clinically active Graves' orbitopathy (GO) before intensive pulse methylprednisolone treatment, $A 1$ patients with clinically active GO after intensive pulse methylprednisolone treatment, $A 2$ patients with clinically active GO 1 month after the end of additional oral methylprednisolone treatment, $C$ control group 


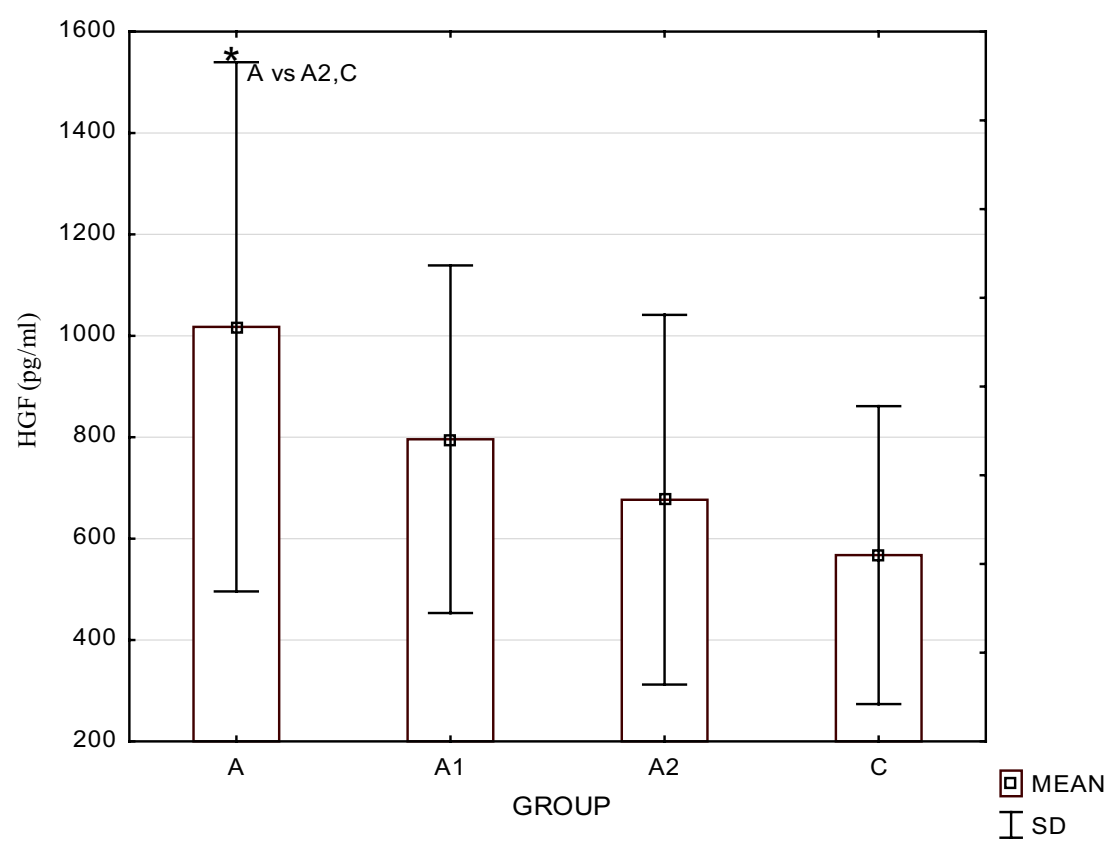

A-patients with clinically active Graves' orbitopathy (GO) before treatment, A1- patients with clinically active GO after intensive pulse methylprednisolone treatment, A2- patients with clinically active GO one month after the end of additional oral methylprednisolone treatment, C- healthy control group

\begin{tabular}{|l|l|l|l|}
\hline & A1 & A2 & C \\
\hline A & 0,670344 & 0,021668 & 0,000574 \\
\hline A1 & - & 1,000000 & 0,109462 \\
\hline A2 & - & - & 1,000000 \\
\hline
\end{tabular}

Fig. 1 Serum concentration of hepatocyte growth factor (HGF, pg/ml) in the studied groups of patients and the significant differences table

We did not find the difference in serum concentration of the studied proangiogenic factors between patients in euthyroid and hyperthyroid stage of Graves' disease before MP therapy (Table 4). Neither did we find any correlation between the studied proangiogenic factors and parameters of autoimmune thyroid disease such as TRAb.

\section{Discussion}

In our previous study, we had found a significant increase in serum concentrations of VEGF and PDGF-AA in the group with active GO before i.v.MP therapy when compared with the control group and a significant decrease in PDGF-AA and insignificant decrease in VEGF serum concentrations after i.v.MP therapy compared with the concentration before treatment. We had found that 1 month after the end of additional oral MP treatment, serum concentration of
PDGF-AA decreased compared to the values after i.v.MP treatment and no significant difference was observed in the value between Group A2 and the control. However, serum concentration of VEGF was still significantly higher as compared to the control $[5,30]$.

In the present study, we found that serum from Graves' patients with clinically active GO exhibited a "proangiogenic" profile, with enhanced serum levels of HGF and IL-8. Concentrations of HGF and IL-8 were significantly higher in the studied group before systemic immunosuppressive therapy when compared to the control. Furthermore, there was a decrease in the concentration of the studied proangiogenic factors after intensive MP therapy with a simultaneous decrease in the activity and severity of GO measured by CAS and NO SPECS score.

Our findings are consistent with several studies demonstrating an increase in serum concentration of proangiogenic factors in patients with Graves' disease [5, 36, 37]. 


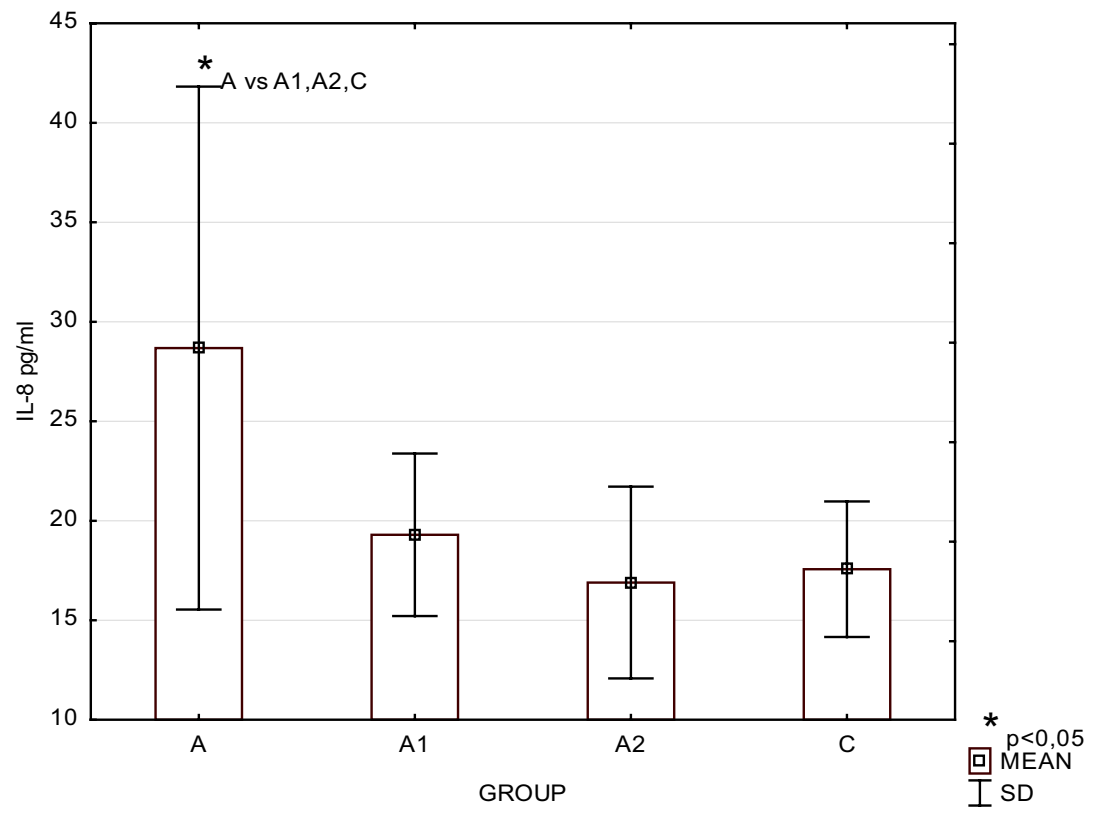

A-patients with clinically active GO before treatment, A1- patients with clinically active GO after intensive pulse methylprednisolone treatment, A2- patients with clinically active GO one month after the end of additional oral methylprednisolone treatment, C- healthy control group

\begin{tabular}{|l|l|l|l|}
\hline & A1 & A2 & C \\
\hline A & 0,000176 & 0,000143 & 0,000163 \\
\hline A1 & - & 0,731829 & 0,884136 \\
\hline A2 & - & - & 0,994079 \\
\hline
\end{tabular}

Fig. 2 Serum concentration of interleukin 8 (IL-8, pg/ml) in the studied groups of patients and the significant differences table

Table 4 Serum concentration of hepatocyte growth factor (HGF) and interleukin-8 (IL-8) in the healthy control group (C) and in patients with active Graves' orbitopathy in euthyroid ( $n=18$, Group A I) and hyperthyroid ( $n=21$, Group A II) stage of thyroid function before methylprednisolone therapy

\begin{tabular}{|c|c|c|c|c|c|c|c|c|c|}
\hline \multirow[t]{2}{*}{ Group } & \multirow[t]{2}{*}{$n$} & \multicolumn{5}{|c|}{$\mathrm{HGF}(\mathrm{pg} / \mathrm{ml})$} & \multicolumn{3}{|l|}{$p$} \\
\hline & & Mean & SD & Median & Min & Max & $\mathrm{C}-\mathrm{AI}$ & C-AII & $\mathrm{AI}-\mathrm{AII}$ \\
\hline $\mathrm{C}$ & 20 & 567 & 294 & 432 & 432 & 1203 & 0.001 & 0.001 & 0.746 \\
\hline A I & 18 & 969 & 363 & 923 & 345 & 1842 & & & \\
\hline A II & 21 & 1101 & 585 & 1001 & 312 & 3018 & & & \\
\hline \multirow[t]{2}{*}{ Group } & $n$ & \multicolumn{5}{|c|}{ Il-8 (pg/ml) } & \multicolumn{3}{|l|}{$p$} \\
\hline & & Mean & SD & Median & Min & Max & $\mathrm{C}-\mathrm{AI}$ & $\mathrm{C}-\mathrm{AII}$ & $\mathrm{AI}-\mathrm{AII}$ \\
\hline $\mathrm{C}$ & 20 & 17.565 & 3.407 & 16.9 & 12.1 & 23.6 & 0.001 & 0.001 & 0.968 \\
\hline A I & 18 & 43.49 & 74.954 & 24.1 & 17.4 & 367.1 & & & \\
\hline A II & 21 & 31.724 & 15.354 & 26.5 & 18.3 & 78.1 & & & \\
\hline
\end{tabular}


However, to the best of our knowledge, our study is the first to evaluate HGF concentration in Graves' disease patients with clinically active GO.

Some authors found that serum VEGF level is elevated in patients with untreated Graves' disease and correlates positively with the degree of thyroid vascularity assessed by colour Doppler ultrasound [37-39]. Other authors found elevated concentrations of PDGF, FGF, IGF-1, and TGF- $\beta 1$ in patients with GO [28, 29, 38, 39].

Angiogenesis is critical for the growth and metastatic spread of tumours and chronic inflammation processes. Although HGF is well characterised as a hepatotrophic [40] and renotrophic factor [41] in liver and kidney regeneration, the presence of the local HGF system (HGF and its receptor-cMET) was demonstrated in both endothelial cells and vascular smooth muscle cells in vivo and in vitro [42]. Hepatocyte growth factor is produced by fibroblasts and other stromal cells and accumulates in the extracellular matrix and in basement membranes, bound to sulphated glycosaminoglycans [43, 44]. Serum level of HGF is a powerful inducer of angiogenesis [31]. Hepatocyte growth factor has an angiogenic action, as well as endotheliumspecific growth action and the effect of HGF is reported to be stronger than that of VEGF $[31,45,46]$. Hepatocyte growth factor is characterised as an important mitogen (stimulation of cell growth), a motogen (stimulation of cell motility), and a morphogen (induction of multicellular tissue-like structure) [47, 48]. It is also a hypoxia-induced secreted protein that binds to cMET and regulates IL-8 expression.

The biological and clinical significance of HGF and its receptor cMET in the thyroid was studied by some authors [48-51]. Thus, overexpression of MET protein might represent an immunohistochemical marker of papillary carcinoma, potentially helpful in problematic cases [50]. MET protein is rarely observed in other thyroid tumours, including follicular carcinoma, anaplastic carcinoma, and medullary carcinoma [50, 51]. MET protein is not present in normal thyroid follicles, but a moderate expression of MET protein is observed in non-neoplastic thyroid diseases, such as Graves' and Hashimoto's thyroiditis [51], some cases of adenomatous goitre, follicular adenoma, and hyperfunctioning goitre [48], which is consistent with our study results.

Interleukin-8 was shown to be an angiogenic factor in 1992 [52]. It plays a significant role in cancerogenesis by mediating angiogenesis [53-57]. Additionally, IL-8 is implicated in a number of inflammatory diseases, such as cystic fibrosis [58], adult respiratory distress syndrome [59], chronic obstructive pulmonary disease, and asthma [60]. Interleukin-8 is secreted by multiple cell types, including monocytes, neutrophils, epithelial, fibroblast, endothelial, and mesothelial cells. It is also detected in tissues related to Graves' disease, such as thyroid tissue, orbital fibroblasts, and the tears and blood of Graves' patients [7, $61,62]$. Interleukin- 8 is released from several cell types in response to an inflammatory stimulus [63-65] and is crucial for wound healing [66]. Interleukin-8 not only serves as a chemotactic factor for leukocytes and fibroblasts but it also stimulates fibroblast differentiation into myofibroblasts and promotes angiogenesis $[67,68]$. Interleukin- 8 is a chemoattractant for neutrophils and induces expression of several cell adhesion molecules and leads to neutrophil activation and hence it may contribute to the pathogenesis of inflammatory diseases $[69,70]$.

Interleukin- 8 is also an oxidative stress-responsive proinflammatory chemokine, released from epithelial cells following particle-induced oxidative stress leading to neutrophil influx and inflammation [71, 72].

Orbital fibroblasts in patients with GO express elevated levels of CD40 ligand and it was found that CD40 ligand and TSH caused up-regulation of IL-8 concentration in orbital fibroblasts of GO patients compared to controls [61, 73].

Huang et al. found higher concentrations of IL-8 in the tears of Graves' disease patients with GO compared to Graves' disease patients without GO [62]. The concentration of IL- 8 was also increased in the orbital adipose tissue in patients with Graves' disease and GO compared to control patients with Graves' disease without GO [7]. These findings suggest that IL-8 may be a mediator of GO activity. Douglas et al. confirmed that stimulation of both TSHR and CD40 plays a role in IL-8 production in circulating fibrocytes. These authors concluded that such stimulation may be a significant pathway for IL-8 production in Graves' disease and GO [74].

In our study, we found a significant increase in IL-8 in the GO group when compared with the control group and a significant decrease after i.v.MP therapy, which is consistent with the results of other authors. One month after the end of additional oral MP treatment, serum concentration of IL-8 still decreased and we did not find the difference with the value in the control group.

Our study supports the observations of Matos et al. who found that patients with a positive expression of proangiogenic factors (FGF, IGF-1, and VEGF) in extraocular eye muscles showed CAS greater than 5, thereby suggesting an important role of these growth factors in the pathogenesis and severity of GO [39].

Glucocorticoids (e.g. MP) modulate VEGF production (and probably also other proangiogenic growth factors) and Ye et al. found that VEGF levels decreased in patients with GO after glucocorticoid treatment, and these changes were accompanied by a decrease in CAS. According to these authors, this decrease could reflect the degree of orbital inflammatory activity [29]. 
Recently, authors have demonstrated elevated PDGF mRNA expression in the orbital tissue from patients with GO [75]. In other studies, authors found that PDGF-BB induces the production of IL-6, IL-8, CCL2, CCL5, and CCL7 by orbital fibroblasts. The above cytokines are involved in the pathogenesis of GO [64]. It is obvious that pathological angiogenesis occurs in inflammatory diseases. The identification of sensitive and specific markers as well as the molecular basis and pathways of diseases with increased angiogenesis should be a challenge for further research. A better understanding of the process may also enable the design of efficient antiangiogenic therapy.

\section{Conclusions}

1. Serum HGF and IL-8 concentrations are elevated in Graves' disease patients with active Graves' orbitopathy as compared to the healthy control group.

2. The elevated serum HGF and IL-8 in patients with active Graves' orbitopathy may reflect long-standing autoimmune inflammatory processes in orbital and thyroid tissues and intensified angiogenesis.

3. Successful management of active Graves' orbitopathy with glucocorticoids is associated with a decrease in HGF and IL-8 serum concentrations.

4. Examination of the proangiogenic factors in the blood of patients with Graves' orbitopathy (in connection with clinical signs measured by CAS and orbit MR scans) could be one of the parameters in the evaluation of Graves' orbitopathy activity and response to the immunosuppressive treatment, however, further studies are still required.

\section{Compliance with ethical standards}

Disclosure of potential conflicts of interest The authors declare that they have no conflict of interest in prepared manuscript. The work was supported by the research program $(\mathrm{KNW}-1-129 / \mathrm{K} / 3 / 0)$ of the Committee of Scientific Research in Poland.

Statement of human rights All procedures performed in the studies involving human participants were in accordance with the ethical standards of the institutional and/or national research committee and with the 1964 Helsinki declaration and its later amendments or comparable ethical standards.

Informed consent Informed consent was obtained from all individual participants included in the study.

Open Access This article is distributed under the terms of the Creative Commons Attribution 4.0 International License (http://creativecommons.org/licenses/by/4.0/), which permits unrestricted use, distribution, and reproduction in any medium, provided you give appropriate credit to the original author(s) and the source, provide a link to the Creative Commons license, and indicate if changes were made.

\section{References}

1. Bartalena L, Fatourechi V (2014) Extrathyroidal manifestations of Graves' disease: a 2014 update. J Endocrinol Invest 37(8):691-700

2. Bartalena Tanda ML (2009) Clinical practice: Graves' ophthalmopathy. N Engl J Med 360(10):994-1001

3. Lazarus JH (2012) Epidemiology of Graves' orbitopathy (GO) and relationship with thyroid disease. Best Pract Res Clin Endocrinol Metab 26:273-279

4. Wiersinga WM, Bartalena L (2002) Epidemiology and prevention of Graves' ophthalmopathy. Thyroid 12:855-860

5. Kajdaniuk D, Marek B, Niedziołka-Zielonka D et al (2014) Transforming growth factor $\beta 1$ (TGF $\beta 1$ ) and vascular endothelial growth factor (VEGF) in the blood of healthy people and patients with Graves' orbitopathy-a new mechanism of glucocorticoids action? Endokrynol Pol 65(5):348-356

6. Seethalakshmi I, Bahn R (2012) Immunopathogenesis of Graves' ophthalmopathy: the role of the TSH receptor. Best Pract Res Clin Endocrinol Metab 26:281-289

7. Kumar S, Bahn RS (2003) Relative overexpression of macrophage-derived cytokines in orbital adipose tissue from patients with graves' ophthalmopathy. J Clin Endocrinol Metab 88:4246-4250

8. Gianoukakis AG, Khadavi N, Smith TJ (2008) Cytokines, Graves' disease, and thyroid-associated ophthalmopathy. Thyroid 18:953-958

9. Khalilzadeh O, Anvari M, Momen-Heravi F et al (2010) Gene polymorphisms of interleukin-4, interleukin-10 and transforming growth factor-beta in Graves' disease. Clin Exp Med 10(2): $123-128$

10. Myśliwiec J, Palyga I, Nikołajuk A, Kowalska A, Górska M (2012) Serum interleukin-16 and RANTES during treatment of Graves' orbitopathy with corticosteroids and teleradiotherapy. Endokrynol Pol 63:92-96

11. Marinò M, Chiovato L, Lisi S, Altea MA, Marcocci C, Pinchera A (2004) Role of thyroglobulin in the pathogenesis of Graves' ophthalmopathy: the hypothesis of Kriss revisited. J Endocrinol Invest 27:230-236

12. Wall JR, Lahooti H (2010) Pathogenesis of thyroid eye diseasedoes autoimmunity against the TSH receptor explain all cases? Endokrynol Pol 61:222-227

13. Effraimidis G, Wiersinga WM (2014) Mechanisms in endocrinology: autoimmune thyroid disease: old and new players. Eur $\mathbf{J}$ Endocrinol 170:241-252

14. Dong YH, Fu DG (2014) Autoimmune thyroid disease: mechanism, genetics and current knowledge. Eur Rev Med Pharmacol Sci 18(23):3611-3618

15. Smith TJ, Hegedus L, Douglas RS (2012) Role of insulin-like growth factor-1 (IGF-1) pathway in the pathogenesis of Graves' orbitopathy. Best Pract Res Clin Endocrinol Metab 26:291-302

16. Mikozami T, Salvi M, Wall JR (2004) Eye muscle antibodies in Graves' ophthalmopathy: pathogenic or secondary epiphenomenon? J Endocrinol Invest 27:221-229

17. Medina J, Arroyo AG, Sanchez-Madrid F, Moreno-Otero R (2004) Angiogenesis in chronic inflammatory liver disease. Hepatology 39:1185-1195

18. Chaparro M, Sanz-Cameno P, Trapero-Marugan M, GarciaBuey L, Moreno-Otero R (2007) Mechanisms of angiogenesis in chronic inflammatory liver disease. Ann Hepatol 6:208-213

19. Carmeliet $P$ (2003) Angiogenesis in health and disease. Nat Med 9:653-660

20. Goth MI, Hubina E, Raptis S, Nagy GM, Toth BE (2003) Physiological and pathological angiogenesis in the endocrine system. Microsc Res Tech 60:98-106 
21. Folkman J, Shing Y (1992) Angiogenesis. J Biol Chem 267:10931-10934

22. Perez-Lopez M, Sales-Sanz M, Robolleda G et al (2011) Retrobulbar ocular blood flow changes after orbital decompression in Graves' ophthalmopathy measured by color Doppler imaging. Invest Ophthalmol Vis Sci 52:5612-5617

23. Kajdaniuk D, Marek B, Borgiel-Marek H, Kos-Kudła B (2011) Vascular endothelial growth factor (VEGF) - part 1: in physiology and pathophysiology. Endokrynol Pol 62:444-455

24. Kajdaniuk D, Marek B, Borgiel-Marek H, Kos-Kudła B (2013) Transforming growth factor beta1 (TGFbeta1) in physiology and pathophysiology. Endokrynol Pol 64:384-396

25. Bartalena L, Baldeschi L, Dickinson AJ et al (2008) Consensus statement of the European Group on Graves' Orbitopathy (EUGOGO) on management of Graves' orbitopathy. Eur J Endocrinol 158:273-285

26. Król A, Koehler A, Nowak M et al (2014) Radioactive iodine (RIA) treatment of hyperthyroidism is safe in patients with Graves' orbitopathy-a prospective study. Endokrynol Pol $65: 40-45$

27. Miśkiewicz P, Kryczka A, Ambroziak U et al (2014) Is high dose intravenous methylprednisolone pulse therapy in patients with Graves' orbitopathy safe? Endokrynol Pol 65(5):402-413

28. Virakul S, van Steensel L, Dalm VASH, Paridaens D, van Hagen PM, Dik WA (2014) Platelet-derived growth factor: a key factor in the pathogenesis of Graves' ophthalmopathy and potential target for treatment. Eur Thyroid J 3:217-226

29. Ye X, Liu J, Wang Y et al (2014) Increased serum VEGF and b-FGF in Graves' ophthalmopathy. Graefes Arch Clin Exp Ophthalmol 252(10):1639-1644

30. Nowak M, Marek B, Karpe J, Kos-Kudla B, Sieminska L, Kajdaniuk D, Treszer M (2014) Serum concentration of VEGF and PDGF-AA in patients with active thyroid orbitopathy before and after immunosuppressive therapy. Exp Clin Endocrinol Diabetes 122:582-586

31. Bussolino F, Di Renzo MF, Ziche M et al (1992) Hepatocyte growth factor is a potent angiogenic factor which stimulates endothelial cell motility and growth. J Cell Biol 119:629-641

32. Nowak M, Wielkoszyński T, Marek B et al (2008) A comparison of the levels of hepatocyte growth factor in serum in patients with type 1 diabetes mellitus with different stages of diabetic retinopathy. Endokrynol Pol 59(1):2-5

33. Wakelkamp IM, Bakker O, Baldeschi L et al (2003) TSH-R expression and cytokine profile in orbital tissue of active versus inactive Graves' ophthalmopathy patients. Clin Endocrinol (Oxf) 58:280-287

34. Cawood TJ, Moriarty P, O'Farrelly C et al (2006) The effects of tumour necrosis factor-alpha and interleukin1 on an in vitro model of thyroid-associated ophthalmopathy; contrasting effects on adipogenesis. Eur J Endocrinol 155:395-403

35. Bartalena L, Krassas EG, Wiersinga $C$ et al (2012) Efficacy and safety of three different cumulative doses of intravenous methylprednisolone for moderate to severe and active Graves' orbitopathy. J Clin Endocrinol Metab 97(12):4454-4463

36. Iitaka M, Miura S, Yamanaka K et al (1998) Increased serum vascular endothelial growth factor levels and intrathyroidal vascular area in patients with Graves' disease and Hashimoto's thyroiditis. J Clin Endocrinol Metab 83:3908-3912

37. Nagura S, Katoh R, Miyagi E, Shibuya M, Kawaoi A (2001) Expression of vascular endothelial growth factor (VEGF) and VEGF receptor-1 (Flt-1) in Graves disease possibly correlated with increased vascular density. Hum Pathol 32:10-17

38. Sato K, Yamazaki K, Shizume K et al (1995) Stimulation by thyroid-stimulating hormone and Grave's immunoglobulin $\mathrm{G}$ of vascular endothelial growth factor mRNA expression in human thyroid follicles in vitro and flt mRNA expression in the rat thyroid in vivo. J Clin Invest 96:1295-1302

39. Matos K, Manso PG, Marback E, Furlanetto G, Alberti DN, Nosé V (2008) Protein expression of VEGF, IGF-1 and FGF in retroocular connective tissues and clinical correlation in Graves' ophthalmopathy. Arq Bras Oftalmol 71:486-492

40. Ishiki Y, Ohnishi H, Muto Y, Matsumoto K, Nakamura T (1992) Direct evidence that hepatocyte growth factor is a hepatotrophic factor for liver regeneration and has a potent antihepatitis effect in vivo. Hepatology 16(5):1227-1235

41. Igawa T, Matsumoto K, Kanda S, Saito Y, Nakamura T (1993) Hepatocyte growth factor may function as a renotropic factor for regeneration in rats with acute renal injury. Am J Physiol 265(1 Pt2):61-69

42. Nakamura Y, Morishita R, Higaki J et al (1995) Expression of a local hepatocyte growth factor system in vascular tissues. Biochem Biophys Res Commun 215:483-488

43. Sonnenberg E, Meyer D, Weidner KM, Birchmeier C (1993) Scatter factor hepatocyte growth factor and its receptor, the c-met tyrosine kinase, can mediate a signal exchange between mesenchyme and epithelia during mouse development. J Cell Biol 123:223-235

44. Kobayashi T, Honke K, Miyazaki T et al (1994) Hepatocyte growth factor specifically binds to sulfoglycolipids. J Biol Chem 269:9817-9821

45. Chiarelli F, Santilli F, Mohn A (2000) Role of growth factors in the development of diabetic complications. Horm Res 53:53-67

46. Cecchi F, Rabe DC, Bottaro DP (2011) The hepatocyte growth factor receptor: structure, function and pharmacological targeting in cancer. Curr Signal Transduct Ther 6:146-151

47. Nakamura T (1994) Hepatocyte growth factor as mitogen, motogen and morphogen, and its roles in organ regeneration. Princess Takamatsu Symp 24:195-213

48. Schulte KM, Antoch G, Ellrichmann M et al (1998) Overexpression of c-met is an important feature of papillary thyroid cancer. Regulation of the HGF-receptor c-met in the thyroid gland. Exp Clin Endocrinol Diabetes 106:310-318

49. Ruco LP, Stoppacciaro A, Ballarini F, Prat M, Scarpino S (2001) Met protein and hepatocyte growth factor (HGF) in papillary carcinoma of the thyroid: evidence for a pathogenetic role in tumourigenesis. J Pathol 194:4-8

50. Ruco LP, Ranalli T, Marzullo A et al (1996) Expression of Met protein in thyroid tumours. J Pathol 180:266-270

51. Trovato M, Villari D, Bartolone L et al (1998) Expression of the hepatocyte growth factor and c-met in normal thyroid, nonneoplastic, and neoplastic nodules. Thyroid 8:125-131

52. Koch AE, Polverini PJ, Kunkel SL et al (1992) Interleukin-8 as a macrophage-derived mediator of angiogenesis. Science 258:1798-1801

53. Kitadai Y, Haruma K, Sumii K et al (1998) Expression of interleukin-8 correlates with vascularity in human gastric carcinomas. Am J Pathol 152:93-100

54. Lingen MW, Polverini PJ, Bouck NP (1996) Retinoic acid induces cells cultured from oral squamous cell carcinomas to become anti-angiogenic. Am J Pathol 149:247-258

55. Schadendorf D, Moller A, Algermissen B, Worm M, Sticherling M, Czarnetzki BM (1993) IL-8 produced by human malignant melanoma cells in vitro is an essential autocrine growth factor. $\mathrm{J}$ Immunol 151:2667-2675

56. Xu L, Fidler IJ (2000) Interleukin 8: an autocrine growth factor for human ovarian cancer. Oncol Res 12:97-106

57. Basolo F, Conaldi PG, Fiore L, Calvo S, Toniolo A (1993) Normal breast epithelial cells produce interleukin 6 and 8 together with tumor-necrosis factor: defective IL6 expression in mammary carcinoma. Int J Cancer 55:926-930 
58. Nakamura H, Yoshimura K, McElvaney NG, Crystal RG (1992) Neutrophil elastase in respiratory epithelial lining fluid of individuals with cystic fibrosis induces interleukin- 8 gene expression in a human bronchial epithelial cell line. J Clin Invest 89:1478-1484

59. Donnelly SC, Strieter RM, Kunkel SL et al (1993) Interleukin-8 and development of adult respiratory distress syndrome in at-risk patient groups. Lancet 341:643-647

60. Marini M, Vittori E, Hollemborg J, Mattoli S (1992) Expression of the potent inflammatory cytokines, granulocyte macrophagecolony-stimulating factor and interleukin- 6 and interleukin- 8 , in bronchial epithelial cells of patients with asthma. J Allergy Clin Immunol 89:1001-1009

61. Hwang CJ, Afifiyan N, Sand D et al (2009) Orbital fibroblasts from patients with thyroid-associated ophthalmopathy overexpress CD40: CD154 hyperinduces IL-6, IL-8, and MCP-1. Invest Ophthalmol Vis Sci 50:2262-2268

62. Huang D, Xu N, Song Y, Wang P, Yang H (2012) Inflammatory cytokine profiles in the tears of thyroid-associated ophthalmopathy. Graefes Arch Clin Exp Ophthalmol 250:619-625

63. Matsushima K, Oppenheim JJ (1989) Interleukin 8 and MCAF: novel inflammatory cytokines inducible by IL 1 and TNF. Cytokine 1:2-13

64. van Steensel L, Paridaens D, Dingjan GM et al (2010) Plateletderived growth factor-BB: a stimulus for cytokine production by orbital fibroblasts in Graves' ophthalmopathy. Invest Ophthalmol Vis Sci 51:1002-1007

65. Qazi BS, Tang K, Qazi A (2011) Recent advances in underlying pathologies provide insight into interleukin-8 expression-mediated inflammation and angiogenesis. Int $\mathrm{J}$ Inflam. doi:10.4061/2011/908468 (Epub 2011 Dec 22)

66. Dobreva I, Waeber G, James RW, Widmann C (2006) Interleukin- 8 secretion by fibroblasts induced by low density lipoproteins is p38 MAPK-dependent and leads to cell spreading and wound closure. J Biol Chem 281:199-205
67. Broughton G II, Janis JE, Attinger CE (2006) The basic science of wound healing. Plast Reconstr Surg 117(supp.7):12-34

68. Vij N, Sharma A, Thakkar M, Sinha S, Mohan RR (2008) PDGF-driven proliferation, migration, and IL8 chemokine secretion in human corneal fibroblasts involve JAK2-STAT3 signaling pathway. Mol Vis 14:1020-1027

69. Koch AE, Kunkel SL, Harlow LA et al (1992) Enhanced production of monocyte chemoattractant protein-1 in rheumatoid arthritis. J Clin Invest 90:772-779

70. Peveri P, Walz A, Dewald B, Baggiolini M (1988) A novel neutrophil-activating factor produced by human mononuclear phagocytes. J Exp Med 167:1547-1559

71. Gilmour PS, Rahman I, Donaldson K, MacNee W (2003) Histone acetylation regulates epithelial IL- 8 release mediated by oxidative stress from environmental particles. Am J Physiol Lung Cell Mol Physiol 284(3):533-540

72. Rosenthal GJ, Germolec DR, Blazka ME et al (1994) Asbestos stimulates IL-8 production from human lung epithelial cells. J Immunol 153:3237-3244

73. Gillespie EF, Papageorgiou KI, Fernando R et al (2012) Increased expression of TSH receptor by fibrocytes in thyroidassociated ophthalmopathy leads to chemokine production. J Clin Endocrinol Metab 97:740-746

74. Douglas RS, Master T, Ginter A, Kim DS (2014) Thyrotropin receptor and CD40 mediate interleukin-8 expression in fibrocytes: implications for thyroid-associated ophthalmopathy (an American Ophthalmological Society thesis). Trans Am Ophthalmol Soc 112:26-37

75. van Steensel L, Paridaens D, Schrijver B et al (2009) Imatinib mesylate and AMN107 inhibit PDGF-signaling in orbital fibroblasts: a potential treatment for Graves' ophthalmopathy. Invest Ophthalmol Vis Sci 50:3091-3098 